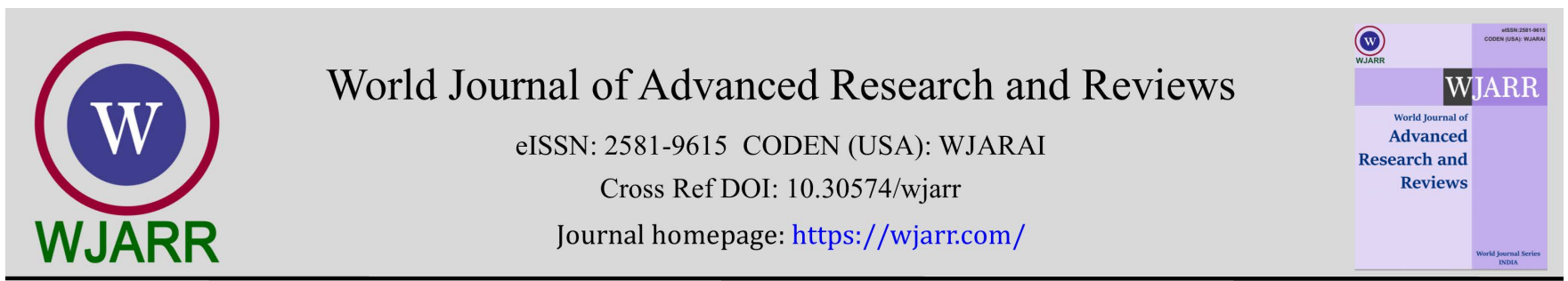

(RESEARCH ARTICLE)

Check for updates

\title{
Pain experience during first trimester medical termination of pregnancy: Clinical observation from a cohort of Asian women
}

\author{
Vincent Y.T. Cheung * \\ Department of Obstetrics and Gynecology, Gleneagles Hospital, The University of Hong Kong, Hong Kong.
}

World Journal of Advanced Research and Reviews, 2022, 13(03), 022-024

Publication history: Received on 25 January 2022; revised on 01 March 2022; accepted on 03 March 2022

Article DOI: https://doi.org/10.30574/wjarr.2022.13.3.0199

\begin{abstract}
Objective: Optimal pain management during medical termination of pregnancy (TOP) remains unclear. This study aimed to suggest practical points to help minimize the intensity of pain of women during first trimester medical TOP.

Methods: A retrospective observational study which reviewed the pain experience and the need for analgesics of 44 Asian women, who underwent first trimester medical TOP.

Results: Nulliparous women had higher pain scores and more likely to need analgesics than multiparous women. Most women requested analgesics between 87.8 and $154.4 \mathrm{~min}$ (95\% confidence interval) after misoprostol administration.

Conclusions: Prophylactic analgesics should be provided to all nulliparous women undergoing first trimester medical TOP; and if paracetamol is the analgesic of choice, it should be given one hour after vaginal misoprostol administration to optimize pain relief.
\end{abstract}

Keywords: First trimester; Medical; Pain management; Termination of pregnancy

\section{Introduction}

Although medical termination of pregnancy (TOP) has been shown to be safe and effective, it is still not commonly utilized in some countries. One of the reasons is the fear of pain during the process of medical TOP. It is generally accepted that women will experience some degree of pain during first trimester medical TOP, and yet optimal pain management remains unclear [1]. Also, practice guidelines on pain management during medical TOP are limited. This study reviewed the pain experience and the need for analgesics in a cohort of Asian women who underwent first trimester medical TOP. Results from this observational study will help facilitate counselling and pain management for women who are going to have this procedure.

\section{Methods}

All pregnancies were assessed clinically and sonographically. First trimester medical TOP was carried out using one of the regimens as recommended by the World Health Organization and the Royal College of Obstetricians and Gynaecologists [2,3]. Mifepristone (200 mg) was given orally at the outpatient clinic followed by misoprostol (800 $\mu \mathrm{g}$ ) administered vaginally as inpatient 24 to 48 hours later. Pain management consisted of oral paracetamol (1000 mg), which was given upon request of the women. Additional intramuscular tramadol (50 mg) was provided if needed for breakthrough pain. After sonographic confirmation of the passage of the abortus, women were asked to describe the

\footnotetext{
${ }^{*}$ Corresponding author: Vincent YT Cheung

Department of Obstetrics and Gynecology, Gleneagles Hospital, The University of Hong Kong, Hong Kong.

Copyright $(2022$ Author(s) retain the copyright of this article. This article is published under the terms of the Creative Commons Attribution Liscense 4.0.
} 
most severe pain intensity she had experienced with a numerical scale from 0 to 10; and for comparison purpose, the pain intensity they experienced during their usual menses.

This study was approved by the Institutional Review Board of the author's institution. Forty-four women, who had first trimester medical TOP between October 2019 and December 2020, were included in this retrospective cohort.

Descriptive statistics were computed for the study cohort. Comparisons between nulliparous and multiparous groups in Table 1 were made using Chi-square test for categorical variables, and Wilcoxon-Mann-Whitney U test for continuous variables. A P value of less than 0.05 was considered statistically significant.

\section{Results}

The demographic and outcome data, with a comparison between nulliparous and multiparous women, are summarized in Table 1. All women had successful passage of gestational sac but four women (9.1\%) subsequently required surgical evacuation of retained gestational products. The mean ( \pm standard deviation) pain scores were $6.7 \pm 1.7$ and $4.0 \pm 1.7$ for nulliparous and multiparous women, respectively; thus accounted for a higher proportion of nulliparous women requesting oral paracetamol (72.4\%, versus 33.3\% of multiparous women). The time interval that most women requested for paracetamol was between 87.8 and $154.4 \mathrm{~min}$ ( $95 \%$ confidence interval) after misoprostol administration (misoprostol-paracetamol interval). Only two women (4.5\%) required additional intramuscular tramadol. $90.9 \%$ of women reported that the pain intensity they experienced were more severe than menstrual pain, irrespective of their parity.

Table 1 Demographic and outcome data

\begin{tabular}{|c|c|c|c|c|}
\hline & Overall $(n=44)$ & $\begin{array}{l}\text { Nullipara } \\
(\mathrm{n}=29)^{*}\end{array}$ & $\begin{array}{l}\text { Multipara } \\
(n=15)[1]\end{array}$ & $*$ p value \\
\hline Age (years) & $29.7 \pm 5.6$ & $27.2 \pm 4.3$ & $34.6 \pm 4.6$ & $<0.0001$ \\
\hline Gestational age (weeks) & $7.1 \pm 1.0$ & $7.0 \pm 0.9$ & $7.4 \pm 1.1$ & 0.1995 \\
\hline Body mass index $(\mathrm{kg} / \mathrm{m} 2)$ & $20.9 \pm 2.8$ & $20.8 \pm 3.1$ & $21.1 \pm 2.3$ & 0.7751 \\
\hline Need for oral paracetamol (number) & $26(59.1 \%)$ & $21(72.4 \%)$ & $5(33.3 \%)$ & 0.0296 \\
\hline Misoprostol-paracetamol interval (min) [2] & $121.1 \pm 80.7[3]$ & $120.8 \pm 85.4$ & $122.5 \pm 58.4$ & 0.9703 \\
\hline Misoprostol-tissue interval (min) [4] & $\begin{array}{l}236.7 \\
(n=39)\end{array} \quad \pm 78.2$ & $\begin{array}{l}237.6 \pm 86.5 \\
(n=27)\end{array}$ & $\begin{array}{l}234.6 \pm 58.8 \\
(n=12)\end{array}$ & 0.9134 \\
\hline Pain score during medical TOP & $5.8 \pm 2.1$ & $6.7 \pm 1.7$ & $4.0 \pm 1.7$ & $<0.0001$ \\
\hline Pain score during menses & $2.6 \pm 2.2$ & $3.4 \pm 2.1$ & $1.1 \pm 1.3$ & 0.0006 \\
\hline $\begin{array}{l}\begin{array}{l}\text { Abortion more painful than menses } \\
\text { (number) }\end{array} \\
\end{array}$ & $40(90.9 \%)$ & $27(93.1 \%)$ & $13(86.7 \%)$ & 0.5962 \\
\hline
\end{tabular}

\section{Discussion}

Pain management is increasingly essential to ensure quality care during medical TOP. During pre-TOP counselling, incorporating a discussion about pain expectations and management strategies could improve the quality of care and experience of each woman facing a medical TOP process. To our knowledge, very few studies have addressed the pain experience during medical TOP specifically in Asian women. This study shows that, during first trimester medical TOP, most women will experience pain, which is of higher intensity than menstrual pain; and a large proportion of nulliparous women will require analgesics (Table 1). By integrating the time interval when most women requested for paracetamol in this study cohort (misoprostol-paracetamol interval, Table 1) and an onset of action of 30 minutes for paracetamol [4], the following practical points are suggested to help minimize the degree of pain during first trimester medical TOP: prophylactic analgesics (instead of giving upon request) should be provided to all nulliparous women; and if paracetamol is the analgesic of choice, it should be given one hour after vaginal misoprostol administration to optimize pain relief during the process. 


\section{Conclusion}

Optimal pain management should be provided to all women undergoing first trimester medical TOP.

\section{Compliance with ethical standards}

\section{Disclosure of conflict of interest}

None declared.

\section{Statement of informed consent}

Informed consent was not required in light of the retrospective and observational nature of this study.

\section{References}

[1] Fiala C , Cameron S , Bombas T, Parachini M, Agostini A, Lertxundi R, et al. Pain management for up to 9 weeks medical abortion - An international survey among abortion providers. Eur J Obstet Gynecol Reprod Biol 2018; 225:181-4.

[2] World Health Organization. Medical management of abortion. 2018.

[3] Royal College of Obstetricians and Gynaecologists. Best practice in comprehensive abortion care. Best Practice Paper No. 2. June 2015.

[4] Twycross R, Pace V, Mihalyo M, Wilcock A. Acetaminophen (paracetamol). J Pain Symptom Manage. 2013; 46:747-55. 